\title{
Variações microclimáticas no entorno de duas escolas públicas na cidade de Cuiabá/MT
}

Microclimatic variations in surrounding of two public schools in the city of Cuiabá/MT

\author{
Mauro Sergio de França'; Gilda Tomasini Maitelli2; Marta Cristina de Jesus Albuquerque Nogueira ${ }^{3}$ \\ 'Doutorando em Física Ambiental/UFMT \\ ${ }^{2}$ Prof. ${ }^{a}$ Dr ${ }^{a}$ do Programa de Pós-Graduação em Geografia/UFMT \\ ${ }^{3}$ Prof. ${ }^{a}$ Dr $^{a}$ do Programa de Pós-Graduação em Física Ambiental/UFMT
}

\section{Resumo}

A cidade de Cuiabá, localizada na região tropical e centro da América do Sul, destaca-se no cenário nacional pelas altas temperaturas ao longo do ano e pelo acelerado crescimento nas últimas décadas, ocasionando a expansão de seu perímetro e o desenvolvimento das atividades urbanas que provocaram alterações climáticas evidenciadas por vários estudos. Este trabalho teve como objetivo comparar as variáveis climatológicas com uso do solo no entorno de duas escolas públicas em Cuiabá/MT. A metodologia utilizada baseou-se em coletas de dados diários e horários de temperatura e umidade relativa do ar durante um ano (fevereiro de 2011 a janeiro de 2012), obtidas com auxílio de estações meteorológicas automáticas fixas, instaladas na escola estadual Padre Ernesto Camilo Barreto e na escola municipal Nossa Senhora Aparecida. Os resultados obtidos evidenciaram diferenças microclimáticas entre as duas áreas, sendo que os valores registrados na área mais edificada, o entorno da escola Padre Ernesto, apresentou na maioria vezes temperaturas mais elevadas quando comparadas com dados observados na área mais afastada da porção central, o entorno da escola Nossa Senhora Aparecida. Constatou-se que o uso do solo em diferentes áreas urbanas ocasiona microclimas diferenciados.

Palavras-chave: Microclimas, Uso Do Solo, Escolas Públicas, Cuiabá

\begin{abstract}
The city of Cuiabá, located in the tropical and central South America, stands out on the national stage by high temperatures throughout the year and by the accelerated growth in recent decades, causing the expansion of its perimeter and development of urban activities that caused climate evidenced by several studies. This study aimed to compare the microclimatic variables with land use in the vicinity of two public schools in Cuiabá / MT. The methodology was based on data collected daily and hourly temperature and relative humidity for one year (February 2011 to January 2012), obtained with the aid of automatic weather stations fixed, installed in the state school Padre Ernesto Camilo Barreto municipal and school Our Lady of Aparecida. The results showed microclimatic differences between the two areas, and the values recorded in the most built, the school environs Padre Ernesto, presented in most times at higher temperatures compared with observed data in the area farthest from the central portion, and the surroundings school Our Lady of Aparecida. It was found that the use of soil in different urban areas causes different microclimates.
\end{abstract}

Keywords: Microclimates, Land Use, Public Schools, Cuiabá 


\section{INTRODUÇÃO}

O clima da cidade de Cuiabá é caracterizado por apresentar elevadas temperaturas ao longo do ano e duas estações bem definidas, uma chuvosa, entre a primavera e o verão e outra seca, entre o outono e o inverno. A cidade apresentou um significativo crescimento populacional entre as décadas de 1980 e 1990, sendo o responsável pela supressão da vegetação original circundante para a inserção dos usos de solo, originando microclimas urbanos diferenciados.

Esse crescimento acelerado nas últimas décadas proporcionou investimentos públicos em diversos setores, entre eles a educação, onde foram ampliadas e construídas novas unidades escolares para atender a demanda. Porém, muitas escolas situavam em áreas com o uso e ocupação do solo definidos ou em definição e que, na maioria das vezes, o poder público não dispunha de recursos e políticas que viessem a proporcionar a recuperação desses locais, principalmente com implantação de áreas verdes e corpos d'água, que poderiam de alguma maneira contribuir para amenizar os rigores microclimáticos e criar ambientes mais saudáveis para a população em geral.

Essa realidade foi fundamental na motivação para a realização deste estudo, visto que as experiências docentes evidenciam que os ambientes desconfortáveis podem comprometer negativamente o processo ensino-aprendizagem. Todavia este estudo não procurou analisar os aspectos internos das escolas e muito menos o seu desempenho, mas sim o ambiente externo e suas variáveis microclimáticas, que no caso foram à temperatura e a umidade relativa do ar.

Para Ayoade (2007) "a temperatura pode ser definida em termos do movimento de moléculas, de modo que quanto mais rápido o deslocamento mais elevado será a temperatura". Mais comumente, ela é definida em termos relativos tomando-se por base o grau de calor que um corpo possui. A temperatura é a condição que determina o fluxo de calor que passa de uma substância para outra. O calor desloca-se de um corpo que tem uma temperatura mais elevada para outro com temperatura mais baixa. A temperatura de um corpo é determinada pelo balanço entre a radiação que chega e a que sai e pela sua transformação em calor latente e sensível, portanto, é o grau de calor medido por um termômetro.

Para Frota e Schiffer (2003) a umidade atmosférica é consequência da evaporação das águas e da transpiração das plantas, fenômeno denominado evapotranspiração. Para esses autores a umidade relativa é a relação da umidade absoluta com a capacidade máxima do ar de reter vapor d'água, àquela temperatura. Isto equivale a dizer que a umidade relativa é uma porcentagem da umidade absoluta de saturação.

Algumas pesquisas foram feitas na cidade de Cuiabá para verificar as condições térmicas em ambientes escolares no intuito de encontrar soluções que minimizem o desconforto ambiental e proporcionem melhores condições para o processo de ensino-aprendizagem.

Durante (2000) avaliou as condições de conforto ambiental nas escolas estaduais João Briene de Camargo, Antônio Cesário Neto e Liceu Cuiabano, localizadas na ilha de calor definida por Maitelli (1994) para a cidade de Cuiabá. As salas de aula dessas escolas foram estudadas sob os aspectos térmico, acústico, lumínico e ergonômico, através de avaliação técnica, no qual os parâmetros relativos a esses aspectos foram medidos por meio de instrumentos adequados e, de avaliação perceptual dos alunos, por meio de questionários. Os resultados dessa avaliação pós-ocupação mostram existir relações entre o conforto ambiental das salas de aula e a ocorrência de alguns comportamentos de interesse no processo educacional, bem como, com o rendimento escolar do aluno, o que pode ser identificado pelos índices de aprovação, reprovação e evasão das escolas.

Pereda (2003) estudou a relação clima-aprendizagem em escolas do município de Cuiabá/ MT. O objetivo do estudo se pautou na verificação de que essa cidade apresenta uma das maiores médias de temperatura do País e buscou alertar as autoridades públicas a respeito das condições de aprendizagem nesses locais. A metodologia utilizou-se de dados climáticos disponíveis e técnica adaptada de sobreposição de mapas, sendo um climático e outro urbano. Setenta e nove escolas municipais foram plotadas (onze não foram encontradas no mapa por falta de parâmetros climáticos) e os endereçamentos foram localizados em cada faixa de variação de temperatura. Os resultados demonstraram a percepção do calor por todos os atores e o prejuízo no ensino, principalmente durante os meses de setembro e outubro de cada ano neste município.

Grzybowski (2004) buscou através de medições "in loco", analisar os índices de conforto térmico na Escola Francisco Ferreira Mendes, em Cuiabá/MT. Através das análises dos dados coletados verificou-se que na maioria dos períodos analisados, os valores para os índices de Fanger se 
encontraram acima do índice considerado aceitável de $+0,5$, determinado pela ISO 7730 (1995).

Santos (2008) investigou através de um estudo de caso o desempenho térmico e lumínico em uma escola pública estadual na cidade de Cuiabá/MT. O estudo foi feito em duas salas de aula da unidade escolar através da carta bioclimática de Giovani, sendo identificadas as horas em desconforto, bem como as estratégias bioclimáticas mais adequadas para obtenção do conforto. Observou-se que mesmo os ambientes sendo salubres para o uso a que são destinados, há necessidade de adequação da arquitetura local às reais condições climáticas da cidade, de maneira atenuar o desconforto térmico e lumínico, favorecendo dessa forma a eficiência na utilização da energia elétrica e contribuindo na produção de novos espaços escolares na região, no sentido de otimizar a concepção de ambientes de sala de aula saudáveis que não prejudiquem o processo de ensino-aprendizagem dos estudantes.

O objetivo geral deste estudo é comparar as variações microclimáticas de temperatura e umidade do ar com o uso do solo no entorno de duas escolas públicas localizadas na área urbana de Cuiabá/MT. Os objetivos específicos constaram da elaboração de mapas específicos com auxílio do software ARCGIS 9.3, identificação de classes de uso do solo e análise comparativa entre as variáveis microclimáticas nas duas escolas.

\section{METODOLOGIA}

Para desenvolver este estudo primeiramente foi feito a escolha dos locais para a instalação das estações meteorológicas automáticas, que no caso foram duas escolas públicas na cidade de Cuiabá/ MT, sendo uma municipal, a Escola Municipal de Educação Básica "Nossa Senhora Aparecida" (EMEB NSA), localizada no bairro Novo Colorado; e outra estadual, a Escola Estadual "Padre Ernesto Camilo Barreto" (EE PECB), bairro Jardim Paulista, distando em média $15 \mathrm{~km}$ uma da outra. figura 1.

A área de estudo pode ser visualizada na

Nas escolas foram instaladas sob as caixas d'águas as estações, que eram compostas de psicrômetro, anemômetro e pluviômetro com as seguintes coordenadas: $15^{\circ} 33^{\prime} 59,4^{\prime \prime} \mathrm{S}$ e $56^{\circ} 06^{\prime} 59,5^{\prime \prime} \mathrm{W}$, altitude de 186 metros (EMEB NSA), figura 2, e $15^{\circ} 37^{\prime} 3,22^{\prime \prime} \mathrm{S}$ e $56^{\circ} 05^{\prime} 4,20^{\prime \prime} \mathrm{W}$, altitude de 176 metros (EE PECB), figura 3.

A coleta de dados ocorreu concomitante nos

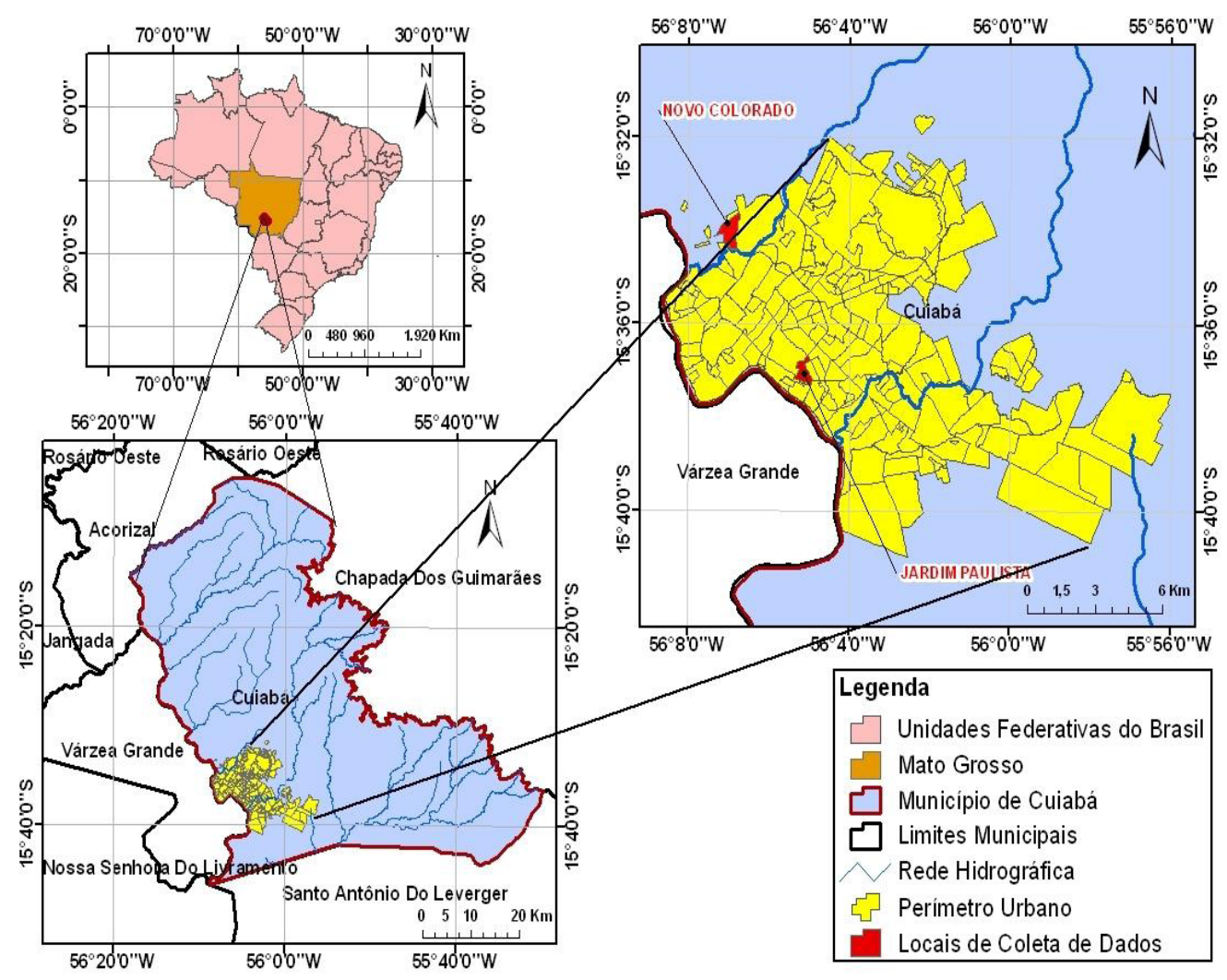

Figura 1 - Localização da área de estudo

Fonte: Base cartográfica do SEPLAN (2009) Elaboração: Costa, L. M. M. (2012) 


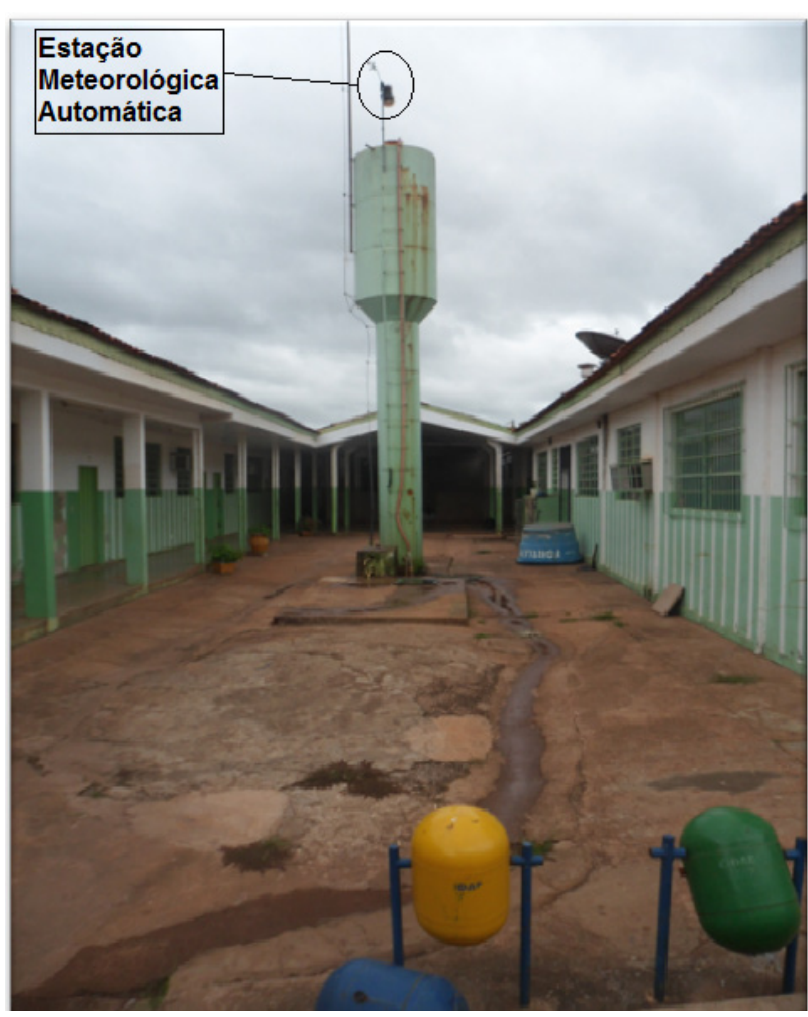

Figura 2: Estação na EMEB NSA, Cuiabá/MT

Foto: França, M. S. (2011)

dois locais com registros diários e horários durante um ano (fevereiro de 2011 a janeiro de 2012). A extração dos dados foi feita bimestralmente utilizando um computador portátil (Notebook), instalado com um software apropriado para esse fim (Weatherlink 5.8.2) e outro para confeccionar planilhas, gráficos e tabelas (Excel 2010).

\section{RESULTADOS}

Para caracterizar o uso do solo no entorno dos locais de coleta dos dados foram utilizados fotografias aéreas que abrangem a área do ano 2005, com articulação: NE_E_IV_1, NE_E_IV_2, NE_E_IV_4, NE_E_IV_5, NO_D_IV_3, SE_A II_1, SE_A_II_2, NE_C_I_4, NE_C_I_5, NE_C_ III_1, NE_C_III_2, NE_C_III_4 e NE_C_III_5, disponibilizadas pela Secretaria Estadual do Meio Ambiente (SEMA, 2001), na escala 1:5000. O SIG utilizado foi o ARC GIS 9.3 e o erro decorrente do registro do georreferenciamento foi de 0,3 pixels, com $1.000 \mathrm{~m}$ de raio (buffer) das estações.

A etapa seguinte foi realizar o mosaico das imagens de alta resolução disponibilizadas no Google Earth do ano de 2009. Em seguida procedeu-se ao pré-processamento das imagens, que consiste na preparação dos dados brutos

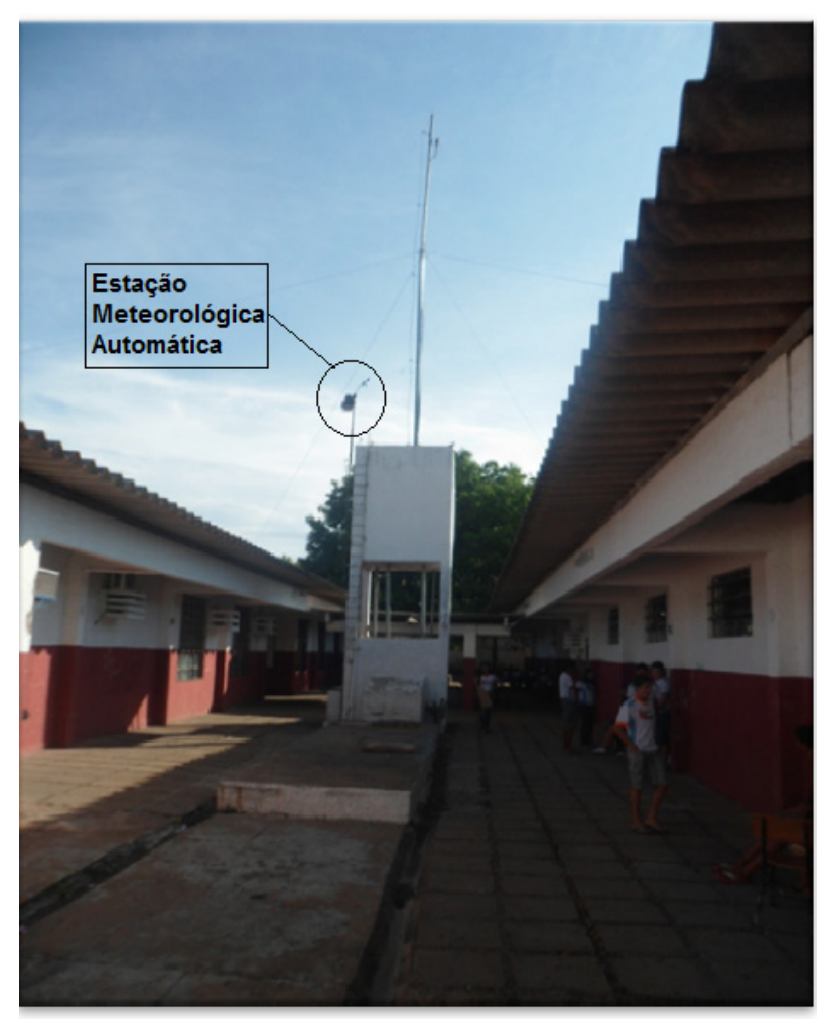

Figura 3: Estação na EE PECB, Cuiabá/MT

Foto: França, M.S. (2011)

da imagem digital, que neste trabalho pode ser classificado pelo mosaico das imagens do Google e o georreferenciamento da imagem, permitindo a análise da cena e a integração em um banco de dados georreferenciados. Essas imagens foram georreferenciadas, etapa caracterizada pelo alinhamento dos pixels da imagem sem referência espacial (Imagem Google) a uma projeção cartográfica. Para isso utilizou-se como base as fotografias aéreas de 2005 que se encontravam ajustadas, a projeção/datum utilizada foi UTM/SAD69-21. As imagens do Google Earth foram utilizadas para atualização das mudanças ocorridas.

O critério utilizado para definir as classes de uso de solo baseou-se no estudo de Cox (2008) que deu ênfase à cobertura do solo através do asfaltamento das vias e áreas construídas, bem como a cobertura vegetal existente, sobretudo por essa característica ser relevante na comparação das variações microclimáticas. Após o pré-processamento das imagens iniciou-se a interpretação visual das imagens com a definição das classes de uso do solo: Área Construída, Arborização Urbana, Pavimentação Asfáltica, Sem Pavimentação Asfáltica, Solo Parcialmente Descoberto, Solo Totalmente Descoberto, Superfície Líquida e Vegetação Remanescente.

O mapeamento das duas áreas observou 


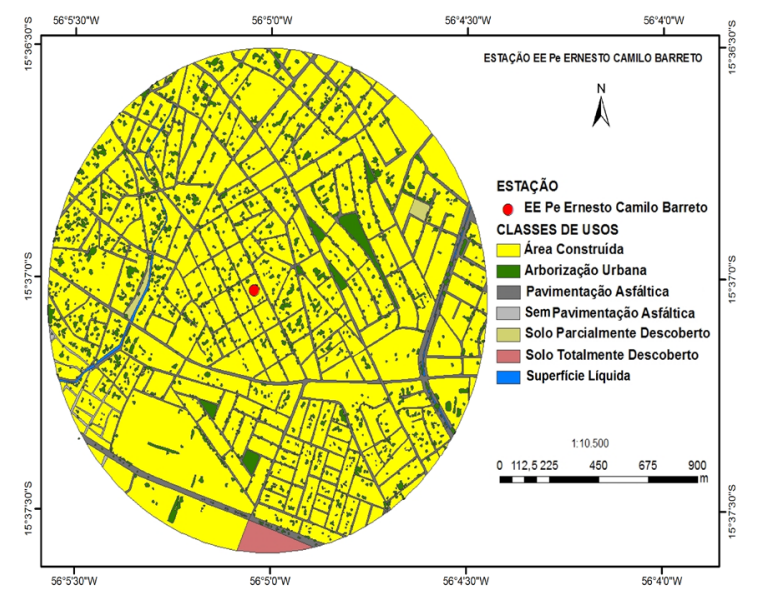

Figura 4: Usos do solo no entorno da EE PECB

Elaboração: Costa, L. M. M. (2012)

diferenças significativas entre o uso e ocupação do solo entre os ambientes (figuras 4 e 5), que foi determinante para a comprovação das variações microclimáticas observadas no estudo.

A distribuição das classes de uso do solo no entorno das áreas mostraram que a área construída e a cobertura vegetal entre os ambientes são distintas contribuindo para evidenciar variações microclimáticas (tabela 1).

Percebe-se o predomínio da área construída no entorno da EE PECB $(78,11 \%)$ e da vegetação remanescente envolta da EMEB NSA $(48,16 \%)$. Essas características são importantes, pois confirmam que as superfícies vegetadas contribuem para amenizar as condições microclimáticas, enquanto áreas densamente construídas favorecem a retenção do calor devido à grande concentração cons-

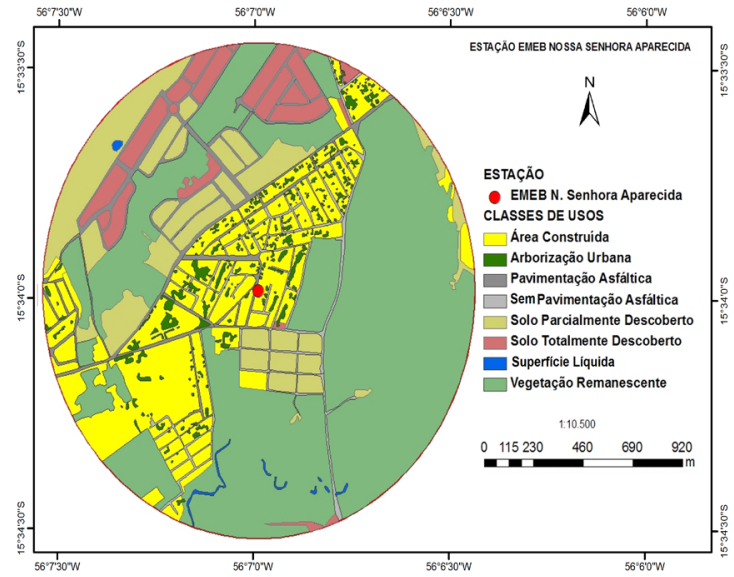

Figura 5: Usos do solo no entorno da EMEB NSA Elaboração: Costa, L. M. M. (2012)

truções e materiais urbanos que absorvem mais radiação solar.

Analisando as médias mensais da temperatura do ar foi possível perceber que o entorno da EE PECB sempre apresentou valores mais elevados de temperatura do ar se comparada à EMEB NSA. As maiores diferenças observadas foram nos meses de junho e julho, embora esse bimestre apresente geralmente temperaturas amenas em alguns dias devido à penetração de frentes frias pelo sul do Estado, onde os valores foram de $24,3^{\circ} \mathrm{C}$ e $24,8^{\circ} \mathrm{C}$ no entorno da EMEB NSA e $25,5^{\circ} \mathrm{C}$ e $26,0^{\circ} \mathrm{C}$ no entorno da EE PECB respectivamente, sendo $1,2^{\circ} \mathrm{C}$ de diferença entre as áreas. Em contrapartida as maiores temperaturas médias do ar ocorreram nos mês de setembro em ambas as estações, registrando valores de $29^{\circ} \mathrm{C}$ e $29,8^{\circ} \mathrm{C}$, respectivamente

Tabela 1: Distribuição dos percentuais das classes de uso do solo no entorno da EE PECB e EMEB NSA, Cuiabá/MT, 2012

\begin{tabular}{c|c|c}
\hline Classes de uso & EE PECB (\%) & EMEB NSA (\%) \\
\hline Arborização urbana & 7,42 & 4,49 \\
\hline Área construída & $\mathbf{7 8 , 1 1}$ & $\mathbf{1 9 , 6 4}$ \\
\hline Sem pavimentação asfáltica & 0,37 & 2,72 \\
\hline Pavimentação asfáltica & 12,57 & 5,31 \\
\hline Solo parcialmente descoberto & 0,34 & 13,41 \\
\hline Solo totalmente descoberto & 0,78 & 5,99 \\
\hline Superfície líquida & 0,41 & 0,28 \\
\hline Vegetação remanescente & $\mathbf{0 , 0 0}$ & $\mathbf{4 8 , 1 6}$ \\
\hline Total & $\mathbf{1 0 0 , 0 0}$ & $\mathbf{1 0 0 , 0 0}$ \\
\hline
\end{tabular}

Elaboração: Costa, L. M. M. (2012) 


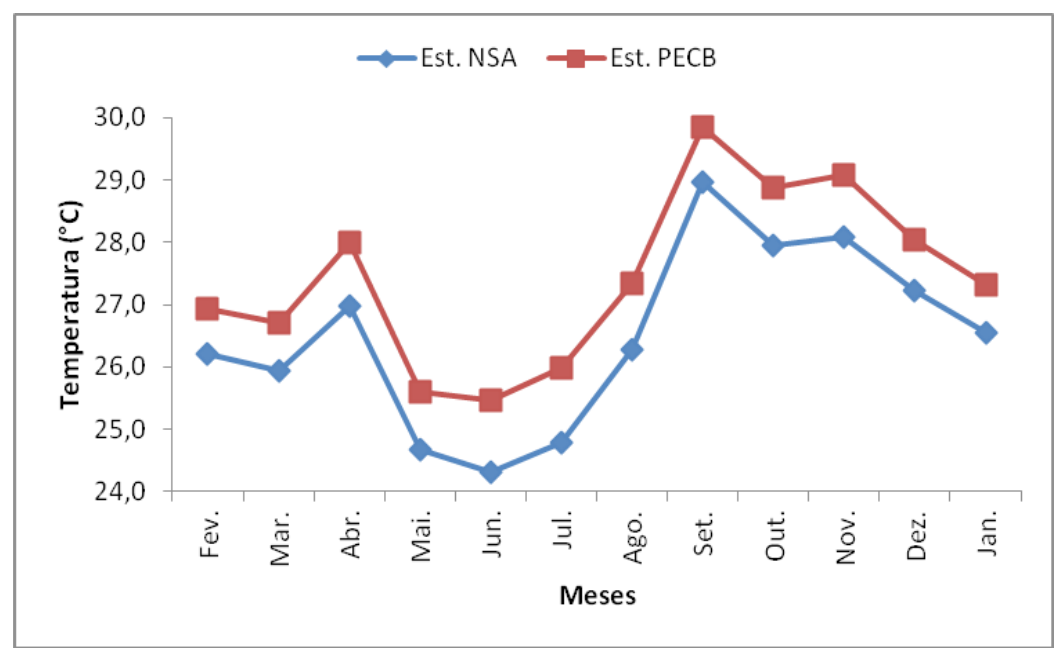

Figura 6: Variações das médias mensais da temperatura do ar entre fevereiro de 2011 e janeiro de 2012, na estação NSA e estação PECB, Cuiabá/MT

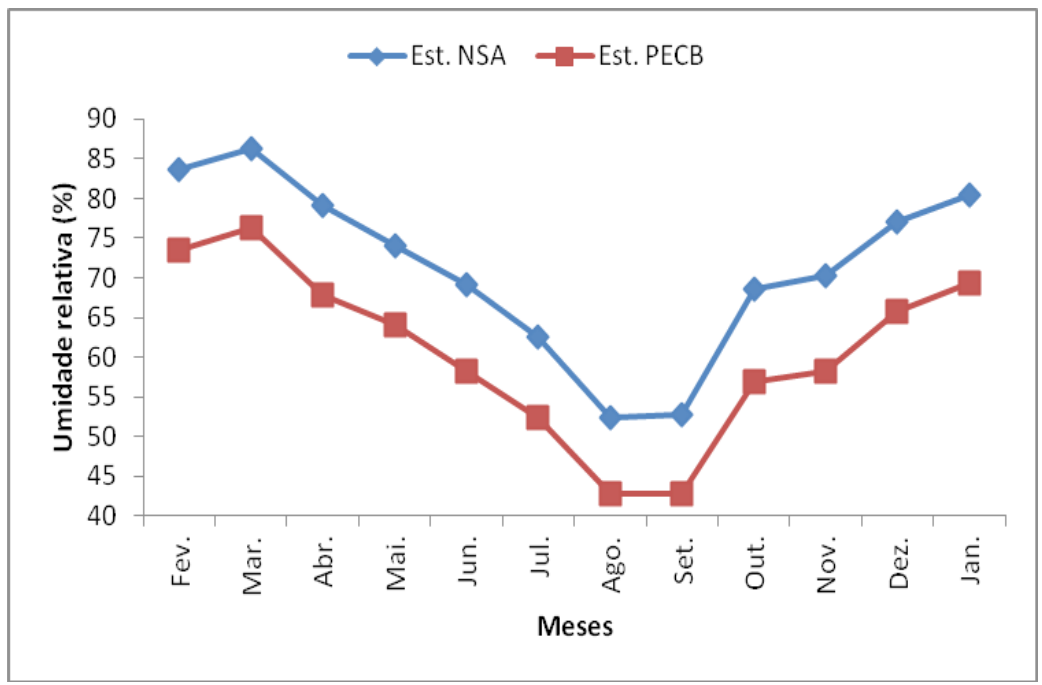

Figura 7: Variações das médias mensais de umidade relativa do ar entre fevereiro de 2011 e janeiro de 2012, na estação NSA e estação PECB, Cuiabá/MT

no entorno da estação NSA e PECB, diferença de $0,8^{\circ} \mathrm{C}$ entre as áreas (figura 6). Possivelmente esse fato pode estar relacionado ao uso e ocupação do solo no entorno daquela unidade escolar, que apresenta uma área densamente construída, que provavelmente influenciou a elevação da temperatura naquele local quando comparado com áreas suburbanas da cidade.

Inversamente proporcional à temperatura, os resultados obtidos com a umidade relativa do ar sempre apresentaram valores mais elevados no entorno da EMEB NSA, que apresentou uma umidade relativa em média, entre 8 a $12 \%$ superior a $\mathrm{EE} P E C B$, que foi mais seca em todos em todo o período. As maiores médias mensais de umidade relativa do ar aconteceram no mês de março, com $86 \%$ de média no entorno da EMEB NSA, contra $76 \%$ em média nos arredores da EE $\mathrm{PECB}$, diferença de 10\% entre as áreas. Esses valores acima de $70 \%$ ocorreram por ser o mês de março típico da estação chuvosa, o que justifica as altas taxas de umidade relativa do ar. As menores médias mensais de umidade relativa ocorreram em agosto, onde no entorno da EMEB NSA registrou uma média uma taxa de $52 \%$ de umidade relativa, bem acima dos $43 \%$ no entorno da EE PECB, diferença de 9\% entre as áreas (figura 7). 


\section{CONCLUSÃO}

Os resultados obtidos evidenciaram que os diversos usos do solo urbano contribuíram para variações microclimáticas de temperatura e umidade relativa do ar. Analisando as médias mensais foi possível perceber que o entorno da EE PECB apresentou ao longo do ano valores mais elevados de temperatura do ar, bem como os menores percentuais de umidade relativa se comparado ao entorno da EMEB NSA. Possivelmente esse fato está relacionado ao uso do solo no entorno daquela unidade escolar, que é essencialmente constituído por área densamente construída, diferentemente do que foi observado na outra área que é caracterizada pelo predomínio de áreas verdes remanescentes, muitas ruas e quintais arborizados e presença de solo descoberto.

\section{REFERÊNCIAS BIBLIOGRÁFICAS}

AYOADE, J. O. Introdução à climatologia para os trópicos. $12^{\mathrm{a}}$ ed. Rio de Janeiro: Bertrand Brasil, 2007.

DURANTE, L. C. Conforto ambiental das escolas estaduais de Cuiabá - MT. 2000. 164 p. Dissertação (Mestrado em Educação) Departamento de Educação, Instituto de Educação, Universidade Federal de Mato Grosso. Cuiabá/MT, 2000.

FROTA, A. B.; SCHIFFER, S. R. Manual de conforto térmico: arquitetura e urbanismo. $7^{\mathrm{a}}$ ed. São Paulo: Stúdio Nobel, 2003.

GRZYBOWSKI, G. T. Conforto térmico nas escolas públicas de Cuiabá - MT: Estudo de caso. 2004. 97 p. Dissertação (Mestrado Física e Meio Ambiente) Departamento de Física, Instituto de Ciências Exatas e da Terra, Universidade Federal de Mato Grosso. Cuiabá/MT, 2004.

MAITELLI, G. T. Uma abordagem tridimensional de clima urbano em área tropical continental: o exemplo de Cuiabá/MT. 1994. 204 p. Tese (Doutorado em Geografia), Departamento de Geografia, Faculdade de Filosofia, Letras e Ciências Humanas da Universidade de São Paulo, São Paulo/SP, 1994.

PEREDA, E. C. A relação clima-aprendizagem nas escolas municipais de Cuiabá - MT. 2003. 163 p. Dissertação (Mestrado em Educação), Departamento de Educação, Instituto de Educação, Uni- versidade Federal de Mato Grosso, Instituto de Educação, 2003.

SANTOS, F. M. M. Análise de desempenho térmico e lumínico em uma escola pública na cidade de Cuiabá/MT: estudo de caso. 2008. 117 p. Dissertação (Mestrado em Física e Meio Ambiente) Departamento de Física, Instituto de Ciências Exatas e da Terra, Universidade Federal de Mato Grosso, Cuiabá/MT, 2008.

VIANELLO, R. L.; ALVES, A. R. Meteorologia básica e aplicações. Viçosa: UFV, 1991. 